\title{
High power light
}

Dentsply will be launching a new product at the Dental Showcase on stand E05-07. SmartLite PS is a pen-style, high power LED Curing Light and has features including no loss of light intensity, short curing times and long-life LED.

It is re-chargeable, its pen-style design ensures easy 'pick and placement' and no fan ensures a silent operation. In addition, the use of Disposa Shield on the LED Tip ensures that cross-contamination procedures are adhered to. The SmartLite PS is totally portable, allowing it to be taken from surgery to surgery. When fully charged the light is operational for a full working day, only requiring charging at the end of the day.

As a special promotion at the show, anyone who orders a SmartLite PS will receive a free promotional pack of QuiXfil, the new posterior composite from Dentsply. Also, visitors will have a chance to win a re-chargeable Maglite every day at the Dental Showcase by filling in an entry form and answering questions on the new product. Reader response number 69

\section{Take your PiC with MEDiVision}

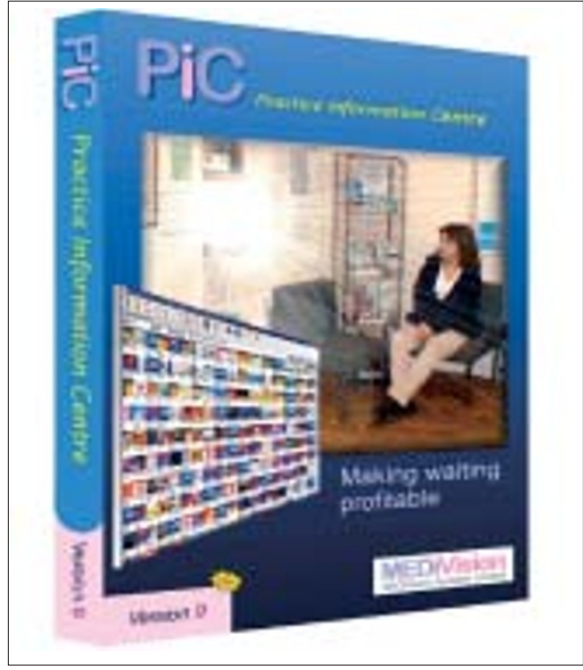

\section{Clothes horse}

Kent Express promises visitors to its stand at R14 and R15 offers on a range of dental sundries, small equipment and the exclusive range of Hejco clothing for dentists and the rest of the dental team.

Reader response number 71

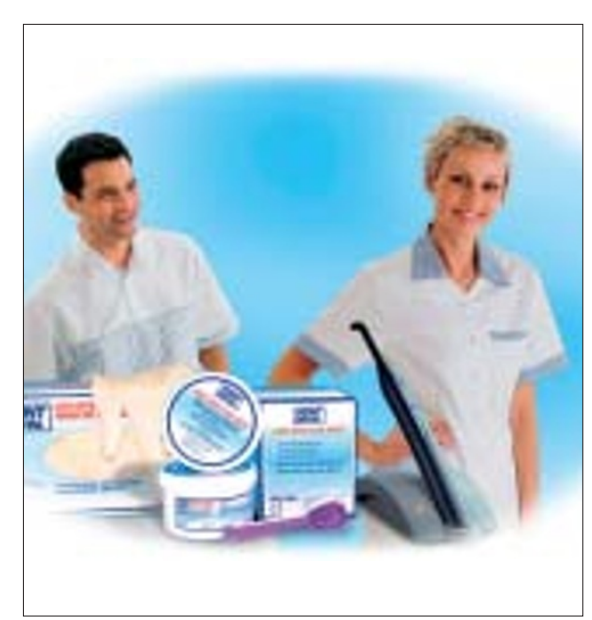

MEDiVision will be announcing the launch of Version 9 of both $\mathrm{CiC}$ Explorer and $\mathrm{PiC}$ at stand B03. The CIC Explorer V9 program for the surgery uses high-tech computer animations to educate and market treatments and procedures. The latest version has even more animations and illustrated patient leaflets.

PIC V9 provides dental marketing for the waiting room. New features include over 200 illustrated and animated messages, new wizard styles and templates to create practice messages. Also available will be the StuDENT program, a training and assessment tool, in the form of an interactive CD ROM.

Reader response number 70

\section{Special offer}

PracticeWorks will be exhibiting its R4 practice management software, which features charting and new courtesy call recall system on stand E11.

During the course of the exhibition all orders placed on the PracticeWorks stand for a networked version of R4, with two or more users, will receive a trophy size one digital $\mathrm{x}$-ray sensor completely free of charge.

Reader response number 72

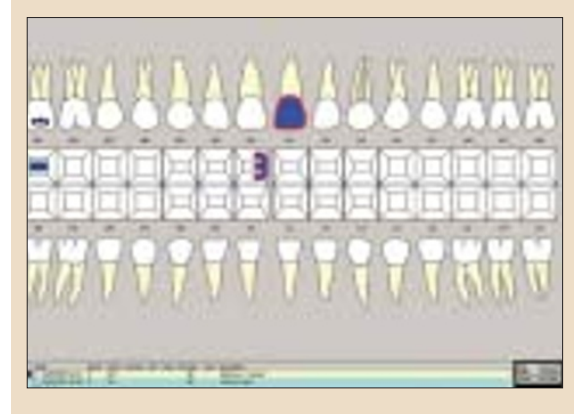

